\title{
The effect of nanoparticle size on the probability to cross the blood-brain barrier: an in-vitro endothelial cell model
}

\author{
Malka Shilo ${ }^{1}$, Anat Sharon ${ }^{2}$, Koby Baranes ${ }^{1}$, Menachem Motiei ${ }^{1}$, Jean-Paul M Lellouche ${ }^{2}$ and Rachela Popovtzer ${ }^{1 *}$
}

\begin{abstract}
Background: During the last decade nanoparticles have gained attention as promising drug delivery agents that can transport through the blood brain barrier. Recently, several studies have demonstrated that specifically targeted nanoparticles which carry a large payload of therapeutic agents can effectively enhance therapeutic agent delivery to the brain. However, it is difficult to draw definite design principles across these studies, owing to the differences in material, size, shape and targeting agents of the nanoparticles. Therefore, the main objective of this study is to develop general design principles that link the size of the nanoparticle with the probability to cross the blood brain barrier. Specifically, we investigate the effect of the nanoparticle size on the probability of barbiturate coated GNPs to cross the blood brain barrier by using bEnd.3 brain endothelial cells as an in vitro blood brain barrier model.

Results: The results show that GNPs of size $70 \mathrm{~nm}$ are optimal for the maximum amount of gold within the brain cells, and that $20 \mathrm{~nm}$ GNPs are the optimal size for maximum free surface area.

Conclusions: These findings can help understand the effect of particle size on the ability to cross the blood brain barrier through the endothelial cell model, and design nanoparticles for brain imaging/therapy contrast agents.
\end{abstract}

Keywords: Blood-brain Barrier, Gold Nanoparticles, Barbiturate, bEnd.3 cells, Nanoparticle size

\section{Background}

The diagnosis and therapy of central nervous system (CNS) and brain pathologies, including Parkinson's disease, Alzheimer's disease, epilepsy and glaucoma, are inadequate because of the limited ability to deliver drugs and imaging contrast agents across the blood brain barrier (BBB) [1]. The BBB separates circulating blood from the brain extracellular fluid (BECF) in the CNS and protects the brain from various circulating toxins and infected cells [2]. It is estimated that more than $98 \%$ of small molecular weight drugs and practically $100 \%$ of large molecular weight drugs developed for CNS pathologies do not readily cross the $\mathrm{BBB}$ [3]. Therefore, it is extremely important to investigate the $\mathrm{BBB}$ penetration mechanism in order to treat and prevent brain disorders. To improve brain penetration for therapeutic agents, medicinal chemistry and

\footnotetext{
* Correspondence: rachela.popovtzer@biu.ac.il

${ }^{1}$ Faculty of Engineering \& the Institute of Nanotechnology and Advanced Materials, Bar-Ilan University, Ramat Gan 52900, Israel

Full list of author information is available at the end of the article
}

pharmaceutical technology-based strategies have been explored and developed widely [4].

During the last decade, nanoparticles have gained attention as promising drug delivery agents that can transport across the $\mathrm{BBB}$ and increase the uptake of appropriate drugs in the brain [1,4-6]. Nanoparticles increase the duration of drug circulation in the blood, which facilitates drug ability to interact with specific molecules expressed on the luminal side of $\mathrm{BBB}$ endothelial cells, and consequently to cross the BBB. In addition, nanoparticles can be engineered to provide designed functionalities using standard procedures in nanotechnology [7-10]. The type and number of linkers on the surface of the nanoparticles, as well as the size of the nanoparticles themselves, can be modulated to increase their ability to cross the BBB. Gold nanoparticles (GNPs) have attracted enormous scientific interest due to properties that make them useful for a large variety of biological and chemical applications [11-14]. Their major advantages are the ability to be synthesized at diverse sizes, their chemical stability and their unique optical properties $[7,15,16]$. Their surface has a strong binding 
affinity towards thiol, disulfide and amine groups, which allows by simple chemistry, surface conjugation with various peptides, proteins, antibodies and other biomolecules [17-19]. Most importantly, GNPs can be traced noninvasively in vivo by CT imaging, due to their high atomic number [20-24], and can be quantitatively detected ex vivo by atomic absorption methods.

It has been well demonstrated that the size, coating and surface charge of nanoparticles have a crucial impact on the intracellular uptake process [25]. Several studies, which investigated the effect of the size of nanoparticles on cellular uptake, revealed different conclusions; One study [25] compared between 14, 30, 50, 74 and $100 \mathrm{~nm}$ GNPs and reported that the highest uptake was detected for $50 \mathrm{~nm}$ GNPs, as reported in other studies [26,27], while another group showed that $20 \mathrm{~nm}$ GNP gave the best results [28]. However, differences in material, size and shape of the nanoparticles, variability between receptors (e.g., degree of receptor overexpression) and divergent cell types, make it difficult to draw definite design principles across these studies [25,29].

In the present study, the effect of nanoparticle size on the probability to cross the $\mathrm{BBB}$ was investigated using the bEnd. 3 brain endothelial cell model. The BBB is formed from a single layer of endothelial cells, which are joined by tight junctions, in the cerebrovascular capillaries and end-feet astrocytes that cover the surface area of the capillary. Therefore, the bEnd. 3 model is the first barrier between the blood and the brain and has a critical influence on the probability to cross the BBB. This BBB cellular model has been widely used in the last few years, and is considered an attractive candidate for an in vitro model of the BBB [30-32].

Normal transition through the BBB can be performed by diffusion transport, carrier systems and receptormediated endocytosis [1]. Entrance of GNPs to these cells can indicate penetration through the BBB. This in vitro model does not represent abnormal BBB such as in brain tumors [33].

GNPs of various sizes $(20,50,70$ and $110 \mathrm{~nm})$ were synthesized and coated with barbiturate, which is a molecule that can easily penetrate the BBB [34]. Therefore, coating GNPs with barbiturate molecules will facilitate their penetration through the $\mathrm{BBB}$, both for therapy and imaging applications. While several studies reported that receptor-mediated endocytosis has been shown to be the most efficient transport mechanism through the BBB, especially for large molecules, proteins and nanoparticles $[18,25]$, we hypothesize that there is an interaction between the barbiturate molecule and the brain endothelium that triggers particle uptake (probably through pinocytosis [35]).

\section{Results and discussion}

\section{GNP synthesis, conjugation and characterization}

We have successfully synthesized GNPs in various sizes, ranging from $20 \mathrm{~nm}$ up to $110 \mathrm{~nm}$. Particles size, shape and uniformity were measured using transmission electron microscopy (TEM) and proven to be 20, 50, 70 and $110 \mathrm{~nm}$ diameter spheres (Figure 1). It is demonstrated that the smallest GNPs $(20 \mathrm{~nm})$ have a relatively large size distribution (20\%), while larger GNPs are more homogeneous, with have a very narrow size distribution $(\sim 2 \%)$. The average sizes that were obtained from the TEM were $18 \pm 4 \mathrm{~nm}, 51 \pm 1 \mathrm{~nm}, 67 \pm 1 \mathrm{~nm}$ and $108 \pm 1 \mathrm{~nm}$.

The difference in GNP size was also obtained using UV-vis spectroscopy. Figure 2 shows a correlation between the size of the GNP and its spectrum. It can be seen that when the GNPs are enlarged, there is a red shift in the surface plasmon resonance (SPR) peak of the particles, from $\sim 525 \mathrm{~nm}$ to $\sim 580 \mathrm{~nm}$ [36].

The size difference and efficiency of the GNP coating (both MDDA and barbiturate) were confirmed by the decrease (absolute value) of the zeta-potential and by the UV-vis Plasmon resonance shift and broadening (Figure 3). An expanded signal was observed following each layercoating because the organic substance absorbs more energy from the irradiated light. The GF-GNPs were stable for up to three months, confirmed by retention of their plasmon resonance.

Size distribution of the barbiturate coated GNPs was also determined using DLS (Figure 4). The average sizes obtained from the DLS were $23 \pm 13,65 \pm 22,84 \pm 26$ and $120 \pm 30 \mathrm{~nm}$ for the 20, 50, 70 and $110 \mathrm{~nm}$ GNPs, respectively. The larger size of the particles obtained by the DLS is due to the hydrodynamic diameter of particles. Similar to the TEM results, the $20 \mathrm{~nm}$ GNPs have a relatively large size distribution, while the larger GNPs are found to be more homogeneous.

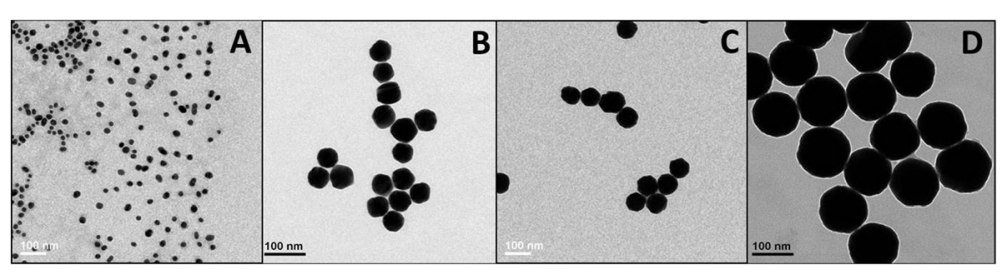

Figure 1 TEM images of (A) 20, (B) 50, (C) 70 and (D) $110 \mathrm{~nm}$ GNPs (scale bar $100 \mathrm{~nm}$ ). 


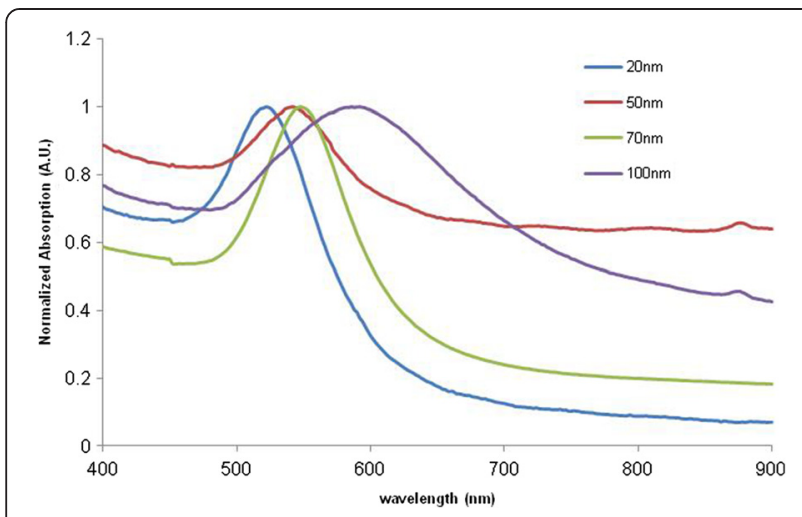

Figure 2 UV-vis spectroscopy of 20, 50, 70 and $110 \mathrm{~nm}$ GNP. Each size exhibits a peak at a different wavelength: 525, 530, 540 and 570 , respectively. When the GNPs are enlarged, there is a red shift in the surface plasmon resonance (SPR) peak of the particles, from $525 \mathrm{~nm}$ to $570 \mathrm{~nm}$.

\section{In vitro cell experiments}

In a control experiment, we compared between the intracellular uptake of barbiturate coated GNPs and mPEG coated nanoparticles, both of size $20 \mathrm{~nm}$. Results showed that barbiturate coated GNPs had high uptake in the bEnd.3 model, while the control GNPs showed a negligible amount of uptake by the cells, which could not be detected by FAAS (Data not shown).

The results showed that intracellular uptake of GNPs is clearly dependent on GNP size. Figure 5 shows the total

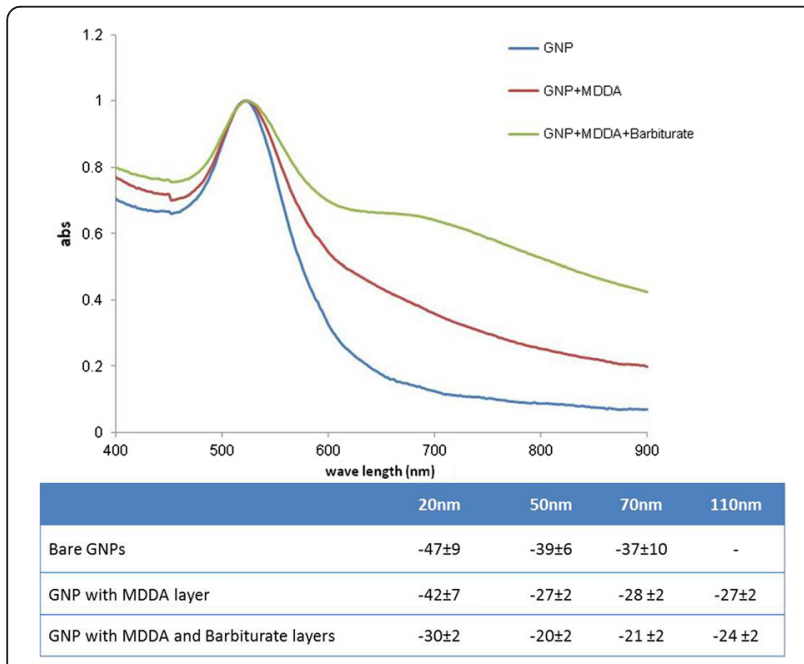

Figure 3 Characterization of the GNPs. Top: UV-vis Spectroscopy of bare GNPs, MDDA coated GNPs and MDDA + Barbiturate coated GNPs, for $20 \mathrm{~nm}$ GNPs. An expanded signal was observed following each layer of coating, confirming the chemical coating. Bottom: zeta-potential measurements at the various stages of GNP coatings for each GNP size. The significant difference obtained (both by zeta-potential and UV-vis Spectroscopy) following each chemical step demonstrates the efficiency of the chemical coating. amount of gold per cell for the various sizes of GNPs (20, 50, 70 and $110 \mathrm{~nm}$ ). Results clearly demonstrate that $70 \mathrm{~nm}$ GNPs produce the largest amounts of gold uptake per cell $(0.21 \pm 0.03 \mathrm{ng}$, about $90 \%$ the GNPs), while for the $20 \mathrm{~nm}$ GNPs the uptake was only $0.12 \pm 0.03 \mathrm{ng}$ (about $50 \%$ of the GNPs) per brain endothelial cell. A T-test performed on these results showed a significant difference ( $P$ value $<0.05$ ) between the different sizes (Figure 5). Once we had quantitatively measured (using FAAS) the total amount of gold bound to a single cancer cell, the exact number of nanoparticles and the GNP surface area per cell could be calculated. When the total free surface area was examined, $20 \mathrm{~nm}$ GNPs had the maximum free surface area per cell. The free surface area decreased with the increase in GNP size (Figure 6). A T-test was performed on these results and showed a significant difference ( $\mathrm{P}$ value $<0.05$ ) between the different sizes. Table 1 shows the total Au mass, the number of GNPs of different sizes and the surface area of the GNPs bound to a single brain endothelial cell.

We have further investigated, using confocal microscopy and fluorescent coated barbiturate-GNPs, the interaction between the nanoparticles and the bEnd. 3 cells. Serial $z$-sections of the cells, each $0.5 \mu \mathrm{m}$ in thickness, demonstrated fluorescence activity in all the sections between 2 and $7 \mu \mathrm{m}$ from the surface of the cells indicating that large part of the nanoparticles were internalized by the cells, while some nanoparticles also bound to the cell surface. Figure 7 shows confocal microscopy of midsection of bEnd. 3 cell after incubation of $30 \mathrm{~min}$ with barbiturate coated GNPs.

Results demonstrated that intracellular uptake of GNPs is strongly dependent on GNP size. Different biomedical applications require different considerations: for example, when GNPs serve as CT contrast agents or as drug delivery carriers (by drug encapsulation into the GNPs), the highest amount of gold is required $(70 \mathrm{~nm})$. However, when GNPs serve as drug delivery carriers by binding the drug molecules to the surface of the GNPs, the highest free surface area is needed, and thus the appropriate size would be $20 \mathrm{~nm}$.

\section{Conclusions}

In order to develop general design principles for nanoparticles to be used as in vivo imaging contrast agents or drug delivery agents, this study investigated the effect of nanoparticle size on the probability to cross the $\mathrm{BBB}$, using the endothelial brain cell model. Results showed that the intracellular uptake of GNPs is dependent on GNP size, and the appropriate size should be determined according to the desired application. These results may accelerate the development of general design principles for GNPs to cross the BBB, and help to meet the great 


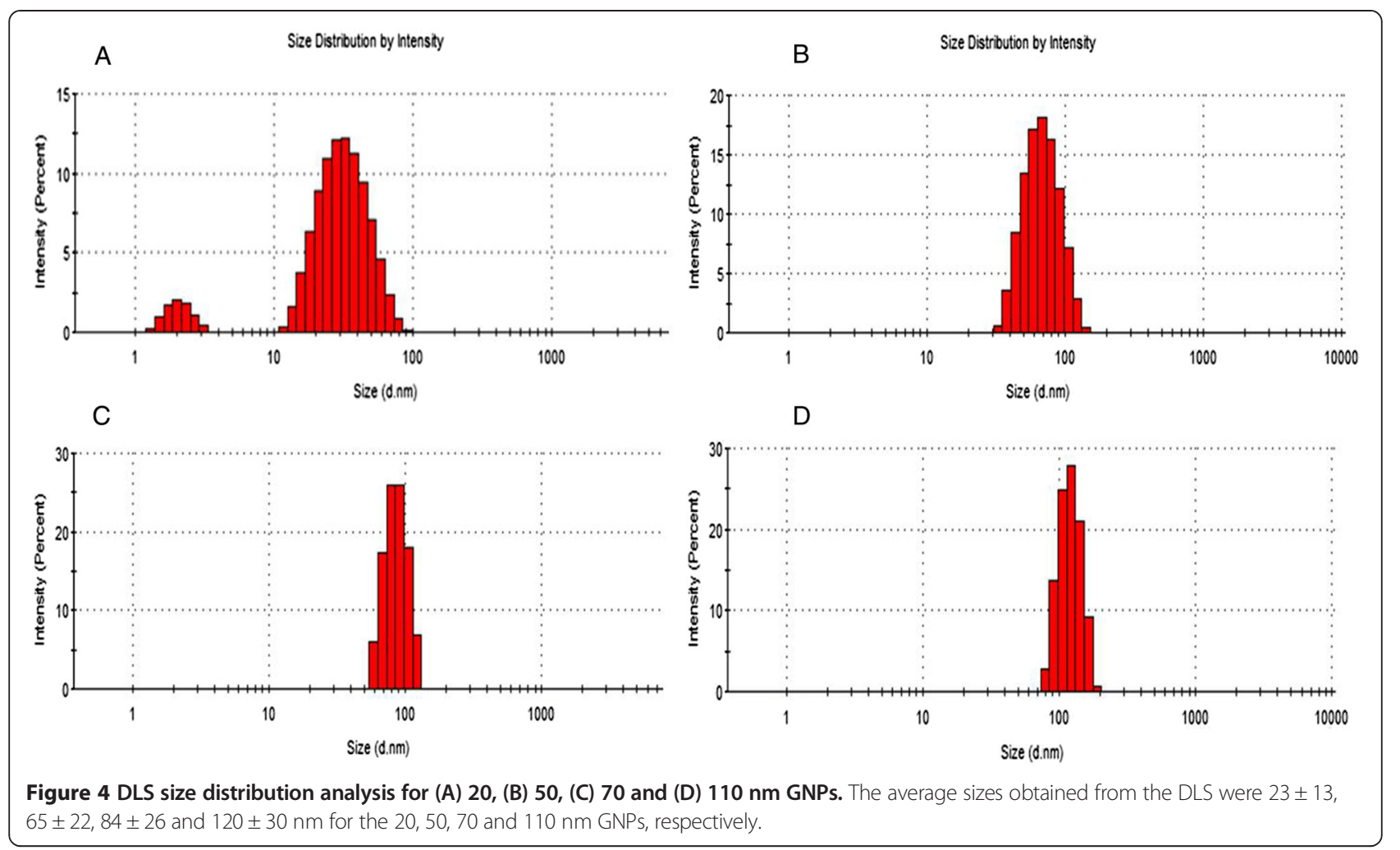

challenge of providing treatments and imaging capabilities for brain diseases and disorders.

\section{Methods}

\section{GNP-synthesis and conjugation}

\section{Synthesis of $20 \mathrm{~nm}$ GNPs}

GNPs were synthesized by citrate reduction of Hydrogen tetrachloroaurate(III) trihydrate $\left(\mathrm{HAuCl}_{4}, \mathrm{Strem}\right)$ [37]. $414 \mu \mathrm{L}$ of $50 \% \mathrm{w} / \mathrm{V}$ of $\mathrm{HAuCl}_{4}$ solution in $200 \mathrm{~mL}$

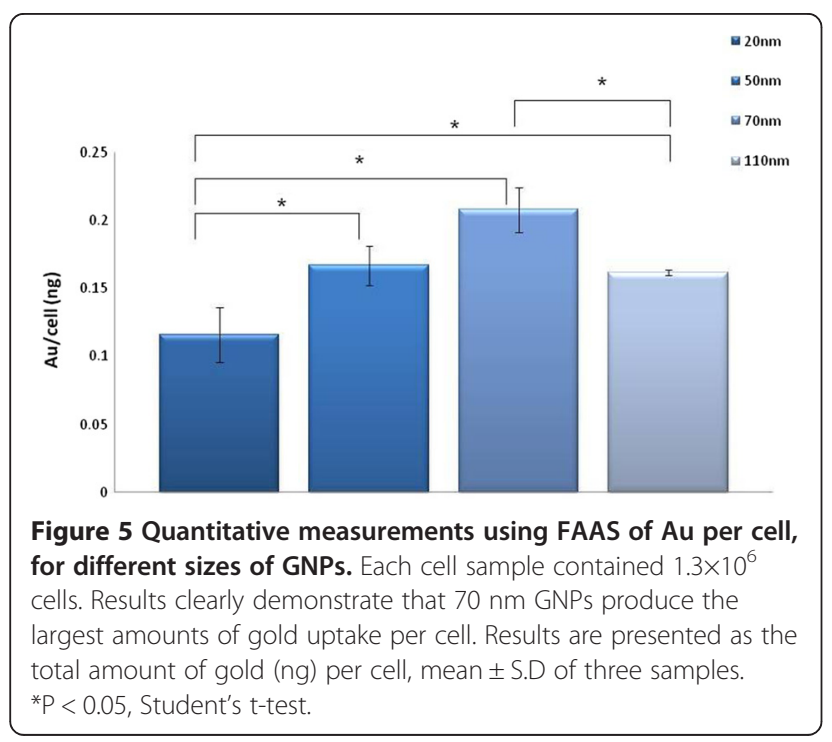

purified water was boiled in an oil bath on a heating plate while being stirred. After boiling, $4 \mathrm{~mL}$ of a $10 \%$ trisodium citrate solution was added and the mixture was stirred while boiling for another 5 minutes. The reducing agent, citrate, has a limited ability to synthesize GNPs that are larger than $30 \mathrm{~nm}$, and therefore, the reducing agent MSA (2-mercaptosuccinic acid, Molekula), which enables synthesis of larger GNPs, was used. For GNP synthesis, $15 \pm 1.5 \mathrm{~nm}$ gold seeds were first prepared. A mixture of MSA and $\mathrm{HAuCl}_{4}$ solutions leads to the growth of the gold seeds. Various amounts of MSA and gold solution were added for each GNP size, as detailed below.

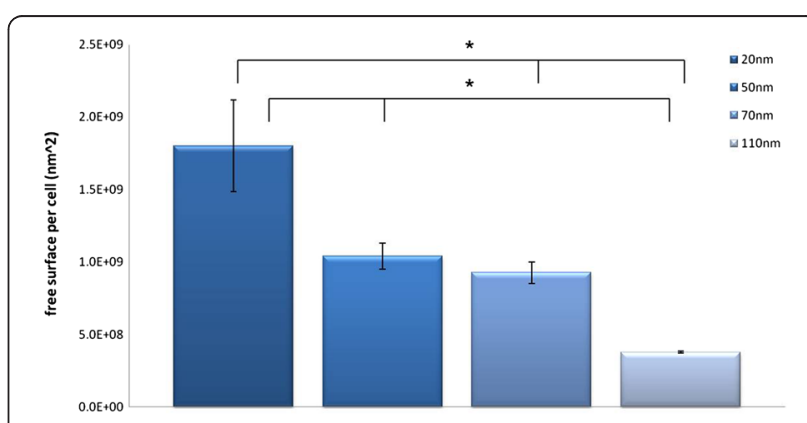

Figure 6 Calculated total free surface area per cell, for different sizes of GNPs. The free surface area decreased with the increase in GNP size. Results are presented as GNP surface area per cell, mean $\pm \mathrm{S}$. $D$ of three samples. ${ }^{*} P<0.05$, Student's t-test. 
Table 1 Quantitative flame atomic absorption measurements of GNP total Au mass (ng), total GNP volume $(\mathrm{nL})$ and total free surface area $\left(\mu \mathrm{m}^{2}\right)$ per single cell

\begin{tabular}{llll}
\hline GNP size $(\mathbf{n m})$ & Au/cell $(\mathbf{n g})$ & Total volume $(\mathbf{n l})$ & Total surface $\left(\boldsymbol{\mu m ^ { 2 }}\right)$ \\
\hline 20 & $0.12 \pm 0.03$ & $6 \mathrm{E}^{-6} \pm 1.05^{-6}$ & $1800 \pm 545$ \\
50 & $0.17 \pm 0.02$ & $8.7^{-6} \pm 7.6^{-7}$ & $1040 \pm 158$ \\
70 & $0.21 \pm 0.03$ & $1.08^{-5} \pm 8.6^{-7}$ & $926 \pm 126$ \\
110 & $0.16 \pm 0.004$ & $8.4^{-6} \pm 1.04^{-7}$ & $379 \pm 8$ \\
\hline
\end{tabular}

For the control experiment, GNPs of size $20 \mathrm{~nm}$ were synthesized and coated with a layer of MethoxyPEG-SH (mPEG-SH). This layer reduces nonspecific interactions and increases blood circulation time of the nanoparticles $[38,39]$.

\section{Synthesis of seed solution for GNPs at 50, 70, and $110 \mathrm{~nm}$}

$10 \mathrm{~mL}$ of purified water was mixed with $10.4 \mu \mathrm{L}$ of $50 \%$ w/V of $\mathrm{HAuCl}_{4}$ solution. The solution was stirred and boiled on a heating plate. To the stirred solution, $100 \mu \mathrm{L}$ of $\mathrm{Na}_{3}$ citrate ( $8.8 \%$ weight percentage) was added and the mixture was stirred and boiled for another 5 minutes (the solution was diluted with water to a volume of $50 \mathrm{~mL}$ ).

\section{Synthesis of 50, 70 and $110 \mathrm{~nm}$ GNPs in Growth solution}

For synthesis of $50 \mathrm{~nm}$ GNPs, $200 \mathrm{~mL}$ of purified water was mixed with $6.5 \mathrm{~mL}$ seed solution. $88 \mu \mathrm{L}$ of $50 \% \mathrm{w} / \mathrm{V}$ of $\mathrm{HAuCl} 4$ and $7.5 \mathrm{~mL} \mathrm{0.04} \mathrm{M}$ MSA solution was added while stirring, and the mixture was stirred for another half hour. For synthesis of $70 \mathrm{~nm}$ GNPs, $176.8 \mu \mathrm{L}$ of $50 \%$ w/V of $\mathrm{HAuCl}_{4}$ solution and $15 \mathrm{~mL} 0.04 \mathrm{M} \mathrm{MSA}$ solution was added while stirring. The mixture was stirred for another half hour. For synthesis of $110 \mathrm{~nm}$ GNPs, another 3 portions of $176.8 \mu \mathrm{L}$ of $50 \% \mathrm{w} / \mathrm{V}$ of $\mathrm{HAuCl}_{4}$ solution and $15 \mathrm{~mL} 0.04 \mathrm{M}$ MSA solution was added after the half hour of stirring.

\section{Conjugation of MDDA and Barbiturate to the GNPs}

The linker MDDA (12-Mercaptododecanoic acid, SigmaAldrich) conjugates between the GNP and the barbiturate. One side of the MDDA chain (thiol) connects to the gold via semi-covalent bonding, while the other side of the MDDA chain, carboxylic acid, binds to the negatively charged oxygen of the barbiturate. To each solution of the various GNP sizes, MDDA was added in excessive amounts, and the mixture was stirred for another four hours. Following this step, the solutions were centrifuged in order to reach higher concentrations. Next, the activating agents EDC (1-Ethyl-3-(3-dimethylaminopropyl) carbodiimide $\mathrm{HCl}$, Thermo Scientific) and NHS (N-Hydroxysulfosuccinimide sodium salt, Chem-Impex International) were added to the mixture together with the barbiturate, and stirred overnight (Figure 8). The solutions were centrifuged again in order to increase concentration.

\section{GNP characterization}

The size, shape and uniformity of the GNPs were measured using transmission electron microscopy (TEM, JEM1400, JEOL). In addition, GNP size was measured using ultraviolet-visible spectroscopy (UV-1650 PC; Shimadzu Corporation, Kyoto Japan) and Dynamic Light Scattering (DLS). Conjugation of the barbiturate to the linkers was verified using Zeta potential and Fourier Transform Infrared (FTIR).

\section{Brain endothelial cell model}

As an in vitro model of the BBB, the mouse brain endothelial cell line (bEnd.3, American Type Culture Collection Manassas, VA) was used [30,31,40]. Cells were grown in DMEM with $4.5 \mathrm{~g} / \mathrm{L}$ glucose, $10 \% \mathrm{FBS}, 3.7 \mathrm{~g} / \mathrm{L}$ sodium bicarbonate, and $4 \mathrm{mM}$ glutamine, and maintained in a humidified cell culture incubator at $37^{\circ} \mathrm{C}$.

\section{In vitro experiments}

Each different sized group of GNPs was incubated with the brain endothelial cells $\left(1.3 \times 10^{6}\right)$ for a quantitative cell uptake study (each experimental group was run in

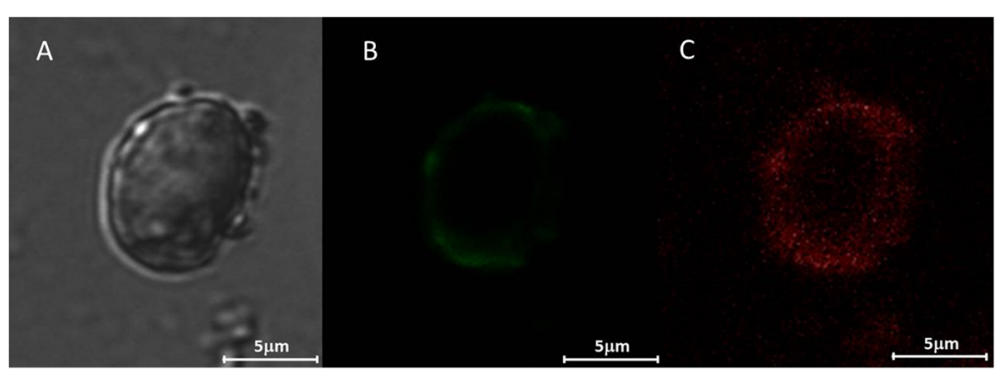

Figure 7 Confocal images of bEnd.3 cells after 30 min of incubation with $70 \mathrm{~nm}$ fluorescent coated barbiturate-GNPs complex. A: A bright field, B: Cell membrane staining and $\mathbf{C}$ : fluorescent coated barbiturate-GNPs. The pictures were taken at the midsection of the cell. Sections were imaged using Leica TCS SP5 with Acousto-Optical Beam Splitter microscope. 


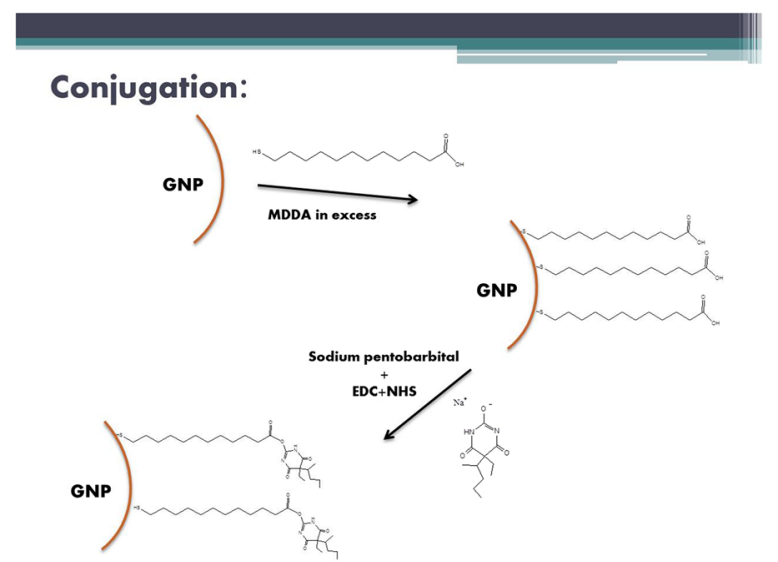

Figure 8 Synthesis of GNPs. Schematic diagram of the synthesis of GNPs and functionalization with barbiturate. In order to conjugate the glucosamine to the GNP, the linker 12-Mercaptododecanoic acid (MDDA) was utilized. EDC and NHS were added in order to activate the carboxylic acids of the linker. One side of the MDDA chain (thiol) connects to the gold via semi-covalent bonding, while the other side, carboxylic acid, binds to the negatively charged oxygen of the barbiturate

triplicate). The procedure was identical for all groups: excessive amounts of GNPs were added to total medium volume of $5 \mathrm{ml}$ (identical amounts of gold per cell) and the incubation time was 30 minutes at $37^{\circ} \mathrm{C}$. The four cell groups were incubated with $10 \mu \mathrm{L}$ of either 20, 50, 70 or $110 \mathrm{~nm}$ GNPs $(30 \mathrm{mg} / \mathrm{mL})$. After incubation, the medium was washed twice with PBS, followed by trypsin treatment. The cells were centrifuged twice (7 minutes at $1000 \mathrm{rpm}$ ) in order to get rid of the unbound nanoparticles. Finally, aqua-regia was added to the cells for ICP-MS gold detection. The total amount of gold was compared between the various GNP sizes.

\section{Quantitative measurements of GNP uptake by brain endothelial cells}

Flame Atomic Absorption Spectroscopy (FAAS, SpectrAA 140, Agilent Technologies) was used in order to determine the amount of the different sized GNPs within the cells. Samples were melted with aqua regia acid (a mixture of nitric acid and hydrochloric acid in a volume ratio of (1:3)), filtered and diluted to a final volume of $5 \mathrm{~mL}$. Gold concentration was determined according to absorbance values, compared to a calibration curve that was prepared with known gold concentrations. All samples were analyzed by FAAS under the same experimental conditions.

\section{Synthesis of fluorescent coated barbiturate-GNPs}

Rodamine $\mathrm{B}$ and PEG-amine were attached to the barbiturate-GNPs by stirring with EDC and NHS for one hour. The mixture was stirred for 3 hours and then centrifuged in order to remove excess rodamone $B$.

\section{Confocal microscopy experiment}

Fluorescent coated barbiturate-GNPs were incubated with the brain endothelial cells for $30 \mathrm{~min}$ at $37^{\circ} \mathrm{C}$. Then, cells were incubated with the fluorescent lipophilic dye, $\mathrm{DiO}$ (Biotium, Inc., Hayward, CA) diluted in DMSO in a final concentration of $10 \mathrm{uM}$ in the culture medium for $15 \mathrm{~min}$ at $37^{\circ} \mathrm{C}$. The cells were subsequently washed three times in PBS prior to confocal imaging using Leica TCS SP5 with Acousto-Optical Beam Splitter microscope to acquire fluorescent and bright field images.

\section{Abbreviations}

BBB: Blood brain barrier; CNS: Central nervous system; BECF: Brain extracellular fluid; GNPs: Gold nanoparticles; TEM: Transmission electron microscopy; SPR: Surface plasmon resonance; DLS: Dynamic Light Scattering; FTIR: Fourier Transform Infrared; FAAS: Flame Atomic Absorption Spectroscopy.

\section{Competing interests}

The authors have declared that no competing interest exists.

\section{Authors' contributions}

MS participated in the design of the study, experiments, performed the statistical analysis and drafted the manuscript. AS prepared the nanoparticles, participated in the design of the study and experiments. KB carried out the confocal microscopy experiment, MM participated in the design of the study and participated in the in vitro experiments, JMP participated in the design of the study, RR participated in the design of the study, results analysis and drafted the manuscript. All authors read and approved the final manuscript.

\section{Acknowledgments}

This work was supported by the Israel Cancer Research Fund (ICRF), by Teva Pharmaceutical Industries Ltd. under the Israeli National Network of Excellence in Neuroscience (NNE) established by Teva and by the Christians for Israel Chair in Medical Research.

\section{Author details}

${ }^{1}$ Faculty of Engineering \& the Institute of Nanotechnology and Advanced Materials, Bar-Ilan University, Ramat Gan 52900, Israel. ${ }^{2}$ The Department of Chemistry \& the Institute of Nanotechnology and Advanced Materials, Bar-llan University, Ramat Gan 52900, Israel.

Received: 21 November 2014 Accepted: 31 January 2015 Published online: 04 March 2015

\section{References}

1. Van Rooy I, Cakir-Tascioglu S, Hennink WE, Storm G, Schiffelers RM, Mastrobattista E. In vivo methods to study uptake of nanoparticles into the brain. Pharm Res. 2011;28:456-71.

2. Abbott NJ, Patabendige AAK, Dolman DEM, Yusof SR, Begley DJ. Structure and function of the blood-brain barrier. Neurobiol Dis. 2010;37:13-25.

3. Pangalos MN, Schechter LE, Hurko O. Drug development for CNS disorders: strategies for balancing risk and reducing attrition. Nat Rev Drug Discov. 2007;6:521-32.

4. Denora N, Trapani A, Laquintana V, Lopedota A, Trapani G. Recent advances in medicinal chemistry and pharmaceutical technology-strategies for drug delivery to the brain. Curr Top Med Chem. 2009;9:182-96.

5. Roney C, Kulkarni P, Arora V, Antich P, Bonte F, Wu A, et al. Targeted nanoparticles for drug delivery through the blood-brain barrier for Alzheimer's disease. J Control Release. 2005;108:193-214.

6. Svenson S, Prud'homme RK. Multifunctional nanoparticles for drug delivery applications. Boston, MA: Springer US; 2012 [Nanostructure Science and Technology].

7. Arvizo R, Bhattacharya R, Mukherjee P. Gold nanoparticles: opportunities and challenges in nanomedicine. Expert Opin Drug Deliv. 2010;7:753-63.

8. Kaur IP, Bhandari R, Bhandari S, Kakkar V. Potential of solid lipid nanoparticles in brain targeting. J Control Release. 2008;127:97-109.

9. Lockman PR, Mumper RJ, Khan MA, Allen DD. Nanoparticle technology for drug delivery across the blood-brain barrier. 2002. 
10. Singh R, Lillard JW. Nanoparticle-based targeted drug delivery. Exp Mol Pathol. 2009:86:215-23.

11. Shilo M, Motiei M, Hana P, Popovtzer R. Transport of nanoparticles through the blood-brain barrier for imaging and therapeutic applications. Nanoscale. 2014;6:2146-52.

12. Jakobsohn K, Motiei M, Sinvani M, Popovtzer R. Towards real-time detection of tumor margins using photothermal imaging of immune-targeted gold nanoparticles. Int J Nanomedicine. 2012;7:4707-13.

13. Sperling RA, Rivera Gil P, Zhang F, Zanella M, Parak WJ. Biological applications of gold nanoparticles. Chem Soc Rev. 2008;37:1896-908.

14. Dykman LA, Khlebtsov NG. Gold nanoparticles in biology and medicine: recent advances and prospects. Acta Nat. 2011:3:34-55.

15. Ghosh P, Han G, De M, Kim CK, Rotello VM. Gold nanoparticles in delivery applications. Adv Drug Deliv Rev. 2008;60:1307-15.

16. Zhang G, Yang Z, Lu W, Zhang R, Huang Q, Tian M, et al. Influence of anchoring ligands and particle size on the colloidal stability and in vivo biodistribution of polyethylene glycol-coated gold nanoparticles in tumor-xenografted mice. Biomaterials. 2009;30:1928-36.

17. Giljohann DA, Seferos DS, Daniel WL, Massich MD, Patel PC, Mirkin CA. Gold nanoparticles for biology and medicine. Angew Chem Int Ed Engl. 2010;49:3280-94

18. Schroedter A, Weller H. Ligand design and bioconjugation of colloidal gold nanoparticles. Angew Chem Int Ed Engl. 2002:41:3218-21.

19. Sperling RA, Parak WJ. Surface modification, functionalization and bioconjugation of colloidal inorganic nanoparticles. Philos Transact A Math Phys Eng Sci. 2010;368:1333-83.

20. Shilo M, Reuveni T, Motiei M, Popovtzer R. Nanoparticles as computed tomography contrast agents: current status and future perspectives. Nanomedicine (Lond). 2012;7:257-69.

21. Curry T, Kopelman R, Shilo M, Popovtzer R. Multifunctional theranostic gold nanoparticles for targeted CT imaging and photothermal therapy. Contrast Media Mol Imaging. 2014;9:53-61.

22. Wang $H$, Zheng L, Guo R, Peng C, Shen M, Shi X, et al. Dendrimer-entrapped gold nanoparticles as potential CT contrast agents for blood pool imaging. Nanoscale Res Lett. 2012;7:190

23. Reuveni T, Motiei M, Romman Z, Popovtzer A, Popovtzer R. Targeted gold nanoparticles enable molecular $C T$ imaging of cancer: an in vivo study. Int J Nanomedicine. 2011:6:2859-64.

24. Kim D, Park S, Lee JH, Jeong YY, Jon S. Antibiofouling polymer-coated gold nanoparticles as a contrast agent for in vivo X-ray computed tomography imaging. J Am Chem Soc. 2007;129:7661-5.

25. Chithrani BD, Ghazani AA, Chan WCW. Determining the size and shape dependence of gold nanoparticle uptake into mammalian cells. Nano Lett. 2006:6:662-8.

26. Osaki F, Kanamori T, Sando S, Sera T, Aoyama Y. A quantum dot conjugated sugar ball and its cellular uptake. On the size effects of endocytosis in the subviral region. J Am Chem Soc. 2004;126:6520-1.

27. Malugin A, Ghandehari H. Cellular uptake and toxicity of gold nanoparticles in prostate cancer cells: a comparative study of rods and spheres. J Appl Toxicol. 2009:30:212-7.

28. Trono JD, Mizuno K, Yusa N, Matsukawa T, Yokoyama K, Uesaka M. Size, concentration and incubation time dependence of gold nanoparticle uptake into pancreas cancer cells and its future application to X-Ray Drug Delivery System. J Radiat Res. 2011;52:103-9.

29. Chithrani DB. Intracellular uptake, transport, and processing of gold nanostructures. Mol Membr Biol. 2010;27:299-311.

30. Camós S, Mallolas J. Experimental models for assaying microvascular endothelial cell pathophysiology in stroke. Molecules. 2010;15:9104-34

31. Brown RC, Morris AP, O'Neil RG. Tight junction protein expression and barrier properties of immortalized mouse brain microvessel endothelial cells. Brain Res. 2007;1130:17-30.

32. Wagner S, Zensi A, Wien SL, Tschickardt SE, Maier W, Vogel T, et al. Uptake mechanism of ApoE-modified nanoparticles on brain capillary endothelial cells as a blood-brain barrier model. PLoS One. 2012;7:e32568.

33. Orive G, Ali OA, Anitua E, Pedraz JL, Emerich DF. Biomaterial-based technologies for brain anti-cancer therapeutics and imaging. Biochim Biophys Acta. 1806;2010:96-107

34. Wong AD, Ye M, Levy AF, Rothstein JD, Bergles DE, Searson PC. The blood-brain barrier: an engineering perspective. Front Neuroeng. 2013;6:7.
35. Tosi G, Fano RA, Bondioli L, Badiali L, Benassi R, Rivasi F, et al. Investigation on mechanisms of glycopeptide nanoparticles for drug delivery across the blood-brain barrier. Nanomedicine (Lond). 2011;6:423-36.

36. Jain PK, Lee KS, El-Sayed IH, El-Sayed MA. Calculated absorption and scattering properties of gold nanoparticles of different size, shape, and composition: applications in biological imaging and biomedicine. J Phys Chem B. 2006;110:7238-48

37. Turkevich J, Stevenson PC, Hillier J. A study of the nucleation and growth processes in the synthesis of colloidal gold. Discuss Faraday Soc. 1951;11:55.

38. Gref R, Lück M, Quellec P, Marchand M, Dellacherie E, Harnisch S, et al. "Stealth" corona-core nanoparticles surface modified by polyethylene glycol (PEG): influences of the corona (PEG chain length and surface density) and of the core composition on phagocytic uptake and plasma protein adsorption. Colloids Surf B: Biointerfaces. 2000;18:301-13.

39. Moghimi SM, Hunter AC, Murray JC. Long-circulating and target-specific nanoparticles: theory to practice. Pharmacol Rev. 2001;53:283-318.

40. Yuan W, Li G, Gil ES, Lowe TL, Fu BM. Effect of surface charge of immortalized mouse cerebral endothelial cell monolayer on transport of charged solutes. Ann Biomed Eng. 2010;38:1463-72.

\section{Submit your next manuscript to BioMed Central and take full advantage of:}

- Convenient online submission

- Thorough peer review

- No space constraints or color figure charges

- Immediate publication on acceptance

- Inclusion in PubMed, CAS, Scopus and Google Scholar

- Research which is freely available for redistribution 